\section{Olive mill wastewater phenolic concentrate as natural antioxi- dant against lipid-protein oxidative deterioration in chicken meat during storage}

\author{
Rossana Roila, ${ }^{1}$ Andrea Valiani, ${ }^{2}$ \\ Dino Miraglia, ${ }^{1}$ David Ranucci, ${ }^{1}$ \\ Claudio Forte, ${ }^{2}$ \\ Massimo Trabalza-Marinucci, ${ }^{1}$ \\ Maurizio Servili, ${ }^{3}$ Michela Codini, ${ }^{4}$ \\ Raffaella Branciari ${ }^{1}$ \\ ${ }^{1}$ Dipartimento di Medicina Veterinaria, \\ Università degli Studi di Perugia; \\ ${ }^{2}$ Istituto Zooprofilattico Sperimentale \\ dell'Umbria e delle Marche "Togo \\ Rosati", Perugia; ${ }^{3}$ Dipartimento di \\ Scienze Agrarie, Alimentari ed \\ Ambientali, Università degli Studi di \\ Perugia; ${ }^{4}$ Dipartimento di Scienze \\ Farmaceutiche, Università degli Studi di \\ Perugia, Italy
}

\section{Abstract \\ Considering that many plant-derived} substances show antioxidant and antimicrobial properties, natural antioxidant administered through feed in livestock animals could increase the shelf life of meat and meat products. The aim of this work was to study the effect of olive oil by-products on chicken meat lipid and protein oxidation and oxidative stability during storage. Two hundred and ninety-seven 22-day-old fast growing (Ross 308) female chicks were randomly assigned to three experimental grower-finisher diets: i) a basal control diet (CTR), ii) CTR diet supplemented with a low dosage $(4.8 \%)$ of olive mill wastewater extract (L-OW) and iii) CTR diet supplemented with a high dosage $(9.9 \%)$ of olive mill wastewater extract (H-OW). Breast meat of animals belonging to each experimental group was sliced, overwrapped with oxygen-permeable packaging and analysed at three different storage times (zero, three and seven days). At the three sampling times considered, for all samples, colour coordinates $\left(\mathrm{a}^{*}\right)$, saturation index, Hue angle, peroxide value, thiobarbituric reactive substance, carbonyl assay and the oxygen radical absorbance capacity determinations were performed. No differences in colour were detected among the groups in all the sampling times considered. In conclusion, the supplementation of chicken diet with olive mill wastewater extract (OW) affected oxidation of meat, retarding lipid and protein oxidation and improving antioxidant activity during storage.

\section{Introduction}

Oxidation is one of the major causes of quality deterioration limiting meat acceptability. Oxidative deterioration, in any type of meat, is responsible for discoloration, development of off-flavour, formation of toxic compounds and short shelf-life. Meat becomes susceptible to oxidative deterioration due to high concentrations of unsaturated lipids, heme pigments in specific species, metal catalysts and a range of oxidizing agents in the muscle tissue (Branciari et al., 2015a).

Oxidation in lipid and protein fractions of meat has been demonstrated as the main non-microbial cause of quality deterioration during processing. This happens because lipids and proteins in meat are easily susceptible to oxidative damages due to the rapid depletion of endogenous antioxidants after slaughter (Xiao et al., 2013). However, the susceptibility of meat to oxidation has also been found to be influenced by animal breed and specie, muscle type and anatomical location (Min et al., 2008). Moreover, the type of diet consumed by animals during the last part of their life has a great influence on the susceptibility of meat to oxidation.

In recent years special attention has been paid to several natural antioxidants (Insani et al., 2008; Ranucci et al., 2013; Roila et al., 2016) that can be applied directly in food as technological strategies or through animal diet to reduce or prevent oxidative process in muscle food (Dal Bosco et al., 2012; Novelli et al., 2014). Technological strategies involve the application of antioxidants directly into the meat and meat products or by coating packaging materials with plant extracts to improve the oxidative stability of the products. In dietary manipulations antioxidants are introduced into the muscle via feed.

Olive oil by-products are amongst those plant derived natural compounds that can be used as potential sources of antioxidants for muscle food preservation and nutritional quality improvement (Branciari et al., 2017) because of their high content of phenolic substances (Novelli et al., 2014). In particular, olive mill wastewater is characterised by a high content in hydroxytyrosol $(3,4$-DHPEA), tyrosol ( $p$ HPEA), secoiridoids derivatives, in particular the dialdehydic form of decarboxymethyl elenolic acid linked to 3,4DHPEA or $p$-HPEA $(3,4$-DHPEA-EDA or $p$-HPEA-EDA) and verbascoside (Branciari
Correspondence: Raffaella Branciari, Dipartimento di Medicina Veterinaria, Università degli Studi di Perugia, Via San Costanzo 4, 06126 Perugia (PG), Italy. Tel.: +39.075.5857932 - Fax: +39.075.5857932. E-mail: raffaella.branciari@unipg.it

Key words: Poultry, TBARS, Carbonyls, Oxidative Stability

Conflict of interest: the authors declare no potential conflict of interest.

Funding: this work is part of a research project funded by the Italian Ministry of Health (RC 007/2012 "Valutazione dell'effetto di una dieta integrata con polifenoli derivanti da reflui dell'industria elaiotecnica sulle caratteristiche igienico-sanitarie, chimico-fisiche, reologiche e organolettiche della carne fresca e delle preparazioni di carne: filiera del pollo da carne").

Received for publication: 13 February 2018 Revision received: 12 June 2018

Accepted for publication: 16 July 2018.

This work is licensed under a Creative Commons Attribution-NonCommercial 4.0 International License (CC BY-NC 4.0).

CCopyright R. Roila et al., 2018

Licensee PAGEPress, Italy

Italian Journal of Food Safety 2018: 7:7342

doi:10.4081/ijfs.2018.7342

et al., 2017). No data are currently available on the effects of dietary supplementation with olive mill wastewater on chicken meat oxidation during storage.

The aim of this work was to evaluate the effect of dietary treatment with olive mill wastewater on lipid and protein oxidative stability during storage.

\section{Materials and Methods}

Two hundred ninety-seven 22-days-old female Ross 308 chicks, previously fed with the same starter diet from day 1 to day 21 , were allocated for a total of 20 days in an experimental farm (Umbria, Italy) under environmental condition simulating those present in conventional intensive systems. The subjects were randomly assigned to one of the three experimental dietary groups and then divided in three replicates of 33 birds each (experimental units). Groups were fed three different diets: a basal grower-finisher control diet (CTR); CTR feed added with low dosage $(4.8 \%)$ of olive mill wastewater (L-OW); CTR feed added with high dosage $(9.9 \%)$ of olive mill wastewater $(\mathrm{H}-\mathrm{OW})$. The diets resulted isoenergetic and 
isonitrogenous and were formulated to meet National Research Council standards for broiler chickens (NRC, 1994). Olive mill waste water polyphenol content of the different feeds was analyzed resulting 263.2 $\mathrm{mg} / \mathrm{kg}$ for the L-OW diet and $556.5 \mathrm{mg} / \mathrm{kg}$ for the H-OW feed. Olive mill wastewater supplement was obtained as reported by Branciari et al. (2016) from processing of Italian cultivar Moraiolo of Olea europea using a filtration system based on progressive permeability membranes.

At the end of the trial, at 41 days of age, the animals were transported and slaughtered at a local slaughterhouse. Immediately after slaughter the carcasses were promptly chilled to $4^{\circ} \mathrm{C}$. After $24 \mathrm{~h}$ the Pectoralis major was removed from carcasses, sliced, randomly assigned to retail packs overwrapped with oxygen-permeable packaging and stored at $4 \pm 1^{\circ} \mathrm{C}$ for 7 days. Packed meat samples were analysed during storage for colour, peroxide value (POV), thiobarbituric reactive substances (TBARS), carbonil assay and $\mathrm{ORAC}_{\mathrm{FL}}$.

\section{Lipid oxidation}

For the evaluation of primary meat lipid oxidation, the POV was determined, during storage, as reported by Branciari et al. (2015b). Secondary meat lipid oxidation was assessed using the TBARS according to Tarladgis et al. (1960); the values were expressed as $\mathrm{mg}$ malondialdehyde (MDA) $/ \mathrm{kg}$.

\section{Protein oxidation}

Protein oxidation, measured by total carbonyl content, was evaluated by derivatization with DNPH according to the method described by Reznick and Packer (1994) with slight modifications: 2 g of meat were thawed, minced and then homogenized $1: 10(\mathrm{w} / \mathrm{v})$ in phosphate buffer $(\mathrm{pH} 7.4)$, consisting of $50 \mathrm{mM} \mathrm{NaH}{ }_{2} \mathrm{PO}_{4}$ and $1 \mathrm{mM}$ EDTA, using an ultraturrax homogenizer for $30 \mathrm{~s}$. The homogenates were divided in two equal aliquots of $0.1 \mathrm{~mL}$. Afterwards proteins were precipitated in both aliquots by adding $1 \mathrm{~mL}$ of $10 \%$ TCA and centrifuged for $5 \mathrm{~min}$ at $5000 \mathrm{rpm}$. Finally, the supernatants were removed, one pellet was treated with $1 \mathrm{~mL} 2 \mathrm{~N} \mathrm{HCl}$ (for quantifying protein concentration) and the other one with an equal volume of $0.2 \%(\mathrm{w} / \mathrm{v}) \mathrm{DNPH}$ in 2 $\mathrm{N} \mathrm{HCl}$ (for carbonyl concentration measurement). Both samples were incubated for $1 \mathrm{~h}$ at room temperature (shaken every $15 \mathrm{~min})$. Afterwards the samples were precipitated with $1 \mathrm{~mL}$ of $10 \%$ TCA and washed twice with $1 \mathrm{~mL}$ of $1: 1$ ethanol/ethyl acetate $(\mathrm{v} / \mathrm{v})$, shaken and centrifuged for 5 min at $10000 \mathrm{rpm}$. The pellets were then dissolved in $1.5 \mathrm{~mL}$ of $20 \mathrm{mM}$ sodium phosphate buffer ( $\mathrm{pH}$ 6.5) containing $6 \mathrm{M}$ guanidine hydrochloride, stirred and centrifuged for $2 \mathrm{~min}$ at $5000 \mathrm{rpm}$ to remove insoluble fragments. Protein concentration was calculated from absorption at $280 \mathrm{~nm}$ using bovine serum albumin as standard.

The number of carbonyls was measured at $370 \mathrm{~nm}$ and expressed as nmol of carbonyl per $\mathrm{mg}$ of protein using the adsorption coefficient for the protein hydrazones (21.0 $\left.\mathrm{mM}^{-1} \mathrm{~cm}^{-1}\right)$.

\section{Colour measurement}

The colour measurement was performed, during each of the sampling intervals, after a 30 minutes bloom period at refrigeration temperature using a CR400 Minolta Chromameter (Minolta, Osaka, Japan - light source of D65 calibrated against a standard white tile). The results were expressed as redness $\left(a^{*}\right)$, hue value $\left(\tan -1 b^{*} / a^{*}\right)$ and saturation index, or chroma $((a * 2+b * 2) 1 / 2)$, (CIE L*a*b* colour system, 1976).

\section{Antioxidant capacity of meat}

The antioxidant capacity of meat (ten samples for each treatment in triplicate) was determined using the oxygen radical absorbance capacity method $\left(\mathrm{ORAC}_{\mathrm{FL}}\right)$ based on the fluorescence decay rate of a probe in the presence of a radical oxygen species (ROO) compared with that of a reference standard, Trolox (6-hydroxy2,5,7,8-tetramethylchroman- 2-carboxylic acid, Sigma-Aldrich, Steinheim, Germany). The extraction was performed on $2 \mathrm{~g}$ of meat sample according to Branciari et al. (2015b).

The $\mathrm{ORAC}_{\mathrm{FL}}$ assays were carried out on a FLUOstar OPTIMA microplate fluorescence reader (BMG LABTECH, Offenburg, Germany) at an excitation wavelength of $485 \mathrm{~nm}$ and an emission wavelength of $520 \mathrm{~nm}$. The procedure was based on the method of Branciari et al. (2015a). Briefly 2,20-azobis (2methylpropionamide) dihydrochloride (AAPH; Sigma-Aldrich) was used as a peroxyl radical generator, Trolox was used as a reference antioxidant standard, and fluorescein was used as fluorescent probe. A $100 \mu \mathrm{L}$ volume of diluted sample, blank or Trolox calibration solution $(10-80 \mu \mathrm{mol})$ was mixed with $1 \mathrm{~mL}$ of fluorescein (80 $\mathrm{nM}$ ), then $200 \mu \mathrm{L}$ of each mixture was placed in a well of the microplate. The microplate was placed in the reader and preincubated for $15 \mathrm{~min}$ at $37^{\circ} \mathrm{C}$. To each well, $60 \mu \mathrm{L}$ of AAPH was automatically added to initiate the reaction. The fluorescence (FL) was measured every 1.9

Table 1. Effect of storage time on peroxide value (POV meq $\mathrm{O}^{2} \mathrm{~kg}^{-1}$ fat), thiobarbituric acid-reactive substances (TBARS mg MDA kg-1) and carbonyls (nmol/mg protein) in breast meat stored at $4^{\circ} \mathrm{C}$

\begin{tabular}{|c|c|c|c|c|}
\hline Days of storage & Sample & POV & TBARS & Carbonyls \\
\hline 0 & $\begin{array}{c}\text { CTR } \\
\text { L-OW } \\
\text { H-OW }\end{array}$ & $\begin{array}{l}1.3 g^{\mathrm{bx}} \\
0.89^{\mathrm{ax}} \\
0.77^{\mathrm{ax}}\end{array}$ & $\begin{array}{c}0.56^{\mathrm{bX}} \\
0.38^{\mathrm{abX}} \\
0.31^{\mathrm{aX}}\end{array}$ & $\begin{array}{l}1.77^{\mathrm{bX}} \\
1.35^{\mathrm{aX}} \\
1.23^{\mathrm{aX}}\end{array}$ \\
\hline 3 & $\begin{array}{c}\text { CTR } \\
\text { L-OW } \\
\text { H-OW }\end{array}$ & $\begin{array}{l}2.35^{\mathrm{bY}} \\
1.63^{\mathrm{a}} \\
1.57^{\mathrm{aY}}\end{array}$ & $\begin{array}{l}0.88^{\mathrm{bY}} \\
0.48^{\mathrm{aY}} \\
0.41^{\mathrm{aY}}\end{array}$ & $\begin{array}{l}1.93^{\mathrm{bY}} \\
1.49^{\mathrm{aX}} \\
1.33^{\mathrm{aY}}\end{array}$ \\
\hline 7 & $\begin{array}{c}\text { CTR } \\
\text { L-OW } \\
\text { H-OW }\end{array}$ & $\begin{array}{l}0.31^{\mathrm{bZ}} \\
0.53^{\mathrm{aZ}} \\
0.61^{\mathrm{ax}}\end{array}$ & $\begin{array}{l}1.60^{\mathrm{bz}} \\
0.76^{\mathrm{az}} \\
0.69^{\mathrm{az}}\end{array}$ & $\begin{array}{l}2.15^{\mathrm{bY}} \\
1.60^{\mathrm{aX}} \\
1.55^{\mathrm{aY}}\end{array}$ \\
\hline SEM & - & 0.09 & 0.132 & 0.078 \\
\hline P-value & $\begin{array}{c}\mathrm{T} \\
\mathrm{D} \\
\mathrm{TXD}\end{array}$ & $\begin{array}{l}<0.001 \\
<0.001 \\
<0.001\end{array}$ & $\begin{array}{l}<0.05 \\
<0.05 \\
0.057\end{array}$ & $\begin{array}{c}<0.001 \\
<0.001 \\
0.897\end{array}$ \\
\hline
\end{tabular}

CTR, meat from chicken fed a standard diet; L-OW, meat from chicken fed enriched diet with low dosage of olive mill wastewater; H-OW, meat from chicken fed enriched diet with high dosage of olive mill wastewater $a, b W i t h i n$ each day of storage, different superscripts indicate differences between dietary treatments $(\mathrm{P}<0.05)$. X,Y,ZWithin each dietary treatment, different superscripts indicate differences between days of storage $(\mathrm{P}<0.05)$.; $\mathrm{T}$, time effect; $\mathrm{D}$, diet effect. 
min. All the reaction mixtures were prepared in duplicate, and at least three independent assays were performed for each sample. The final $\mathrm{ORAC}_{\mathrm{FL}}$ values were calculated by using a linear regression equation $(\mathrm{Y}=\mathrm{a}+$ $\mathrm{bX}$ ) to describe the relationship between the Trolox concentration $(\mathrm{Y})$ and the net area under the FL decay curve (X). Linear regression was used in the range of 10-80 $\mathrm{lM}$ Trolox. The data are expressed as micromoles of Trolox equivalents (TE) per gram of sample ( $\mu$ mol TE $\left.\mathrm{g}^{-1}\right)$ by applying the following formula:

$$
\operatorname{Orac}(\mu \text { molTE })=\frac{\text { Ctrolox }(\text { AUCSample }- \text { AUCBlank }) k}{(\text { AUCTrolox }- \text { AUCBlank })}
$$

where Ctrolox is the concentration of Trolox, $\mathrm{k}$ is the sample dilution factor, and AUC is the area below the fluorescence decay curve of the sample, the blank and Trolox, respectively, calculated by applying the following formula (Ou et al., 2001) in a Microsoft Excel spreadsheet (Microsoft, Washington, DC, USA)

$$
A U C=0.5+f 1 / f 0+\ldots f i / f 0
$$

where $f 1$ is the initial fluorescence reading at $\mathrm{t}=0 \mathrm{~min}$ and $f i$ is the fluorescence reading at time i. The net AUC for each sample was obtained by subtracting the AUC of the corresponding blank from that of the sample.

\section{Statistical analysis}

The data were analysed using the GLM procedure of SAS (2001). ANOVA model was used with diet (CTR, L-OW and H-OW) and time (day 0 , day 3 and day 7 ) as fixed variables. The differences of the means were analysed using Tukey test and were considered to be significant when $\mathrm{P}<0.05$.

\section{Results}

The POV, TBARS values and the amount of carbonyl compounds are reported in Table 1. POVs showed an increase at 3 days of storage than decreased at 7 days. The POV's value was higher in CTR sample at 0 and 3 days of storage. At 7 days of storage higher value of POV was registered for LOW and H-OW than CTR sample, because lipid peroxides were cleaved to yield secondary oxidation products. The analysis of TBARS showed an increase during storage. Higher values for CTR sample than L-OW and H-OW were recorded at 0 and 3 and 7 days of storage.
For the colour parameters considered no difference during storage, neither among samples, were detected for redness ( $\left.a^{*}\right)$, Hue angle and saturation index. The effect of time and diet was evident for all lipid and protein oxidation parameters but no for the color (Figures 1-3).

The results obtained for the $\mathrm{ORAC}_{\mathrm{FL}}$ determinations in meat samples are reported in Figure 4. Differences were recorded for CTR versus L-OW and H-OW groups showing higher values in the antioxidant activity compared to control in all time of storage.

\section{Discussions}

The results of the present study show that supplementing chicken diet with phenolic compounds trough olive oil byproducts protects meat against lipid and protein oxidation. Chemical deterioration, and in particular lipid oxidation, is one of the main factors able to limit the shelf-life of meat. The inclusion of natural antioxidants in animal diets has been reported by various authors as a way to slow down meat lipid oxidation during storage, therefore improving the quality and the conservation of products (Ranucci et al., 2013; Luciano et al., 2013).

The POV value increased and thereafter decreased with the time of storage, moreover the decomposition of hydroperoxides into secondary products appears to increase at a higher rate in the CTR compared with the treated samples. These data are in accordance with those of Hwang et al.

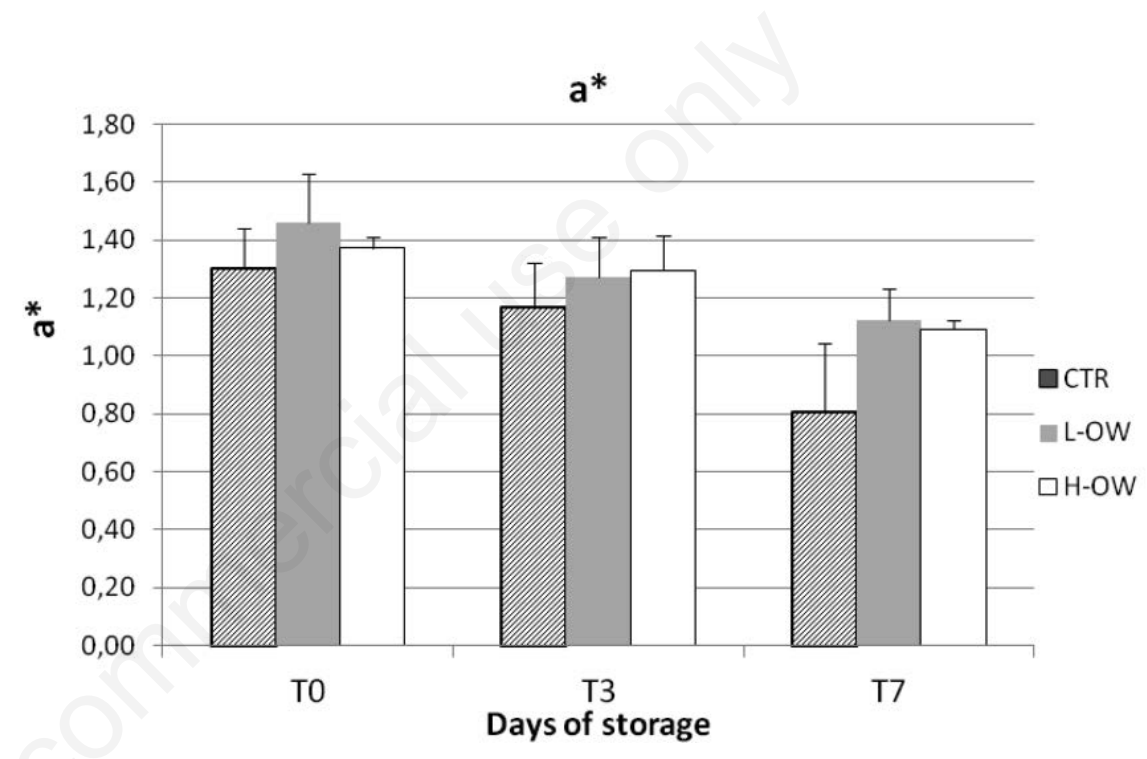

Figure 1. Effect of storage time on $\mathrm{CIE} \mathrm{a}^{*}$ value of breast meat stored at $4^{\circ} \mathrm{C}$.

Hue angle

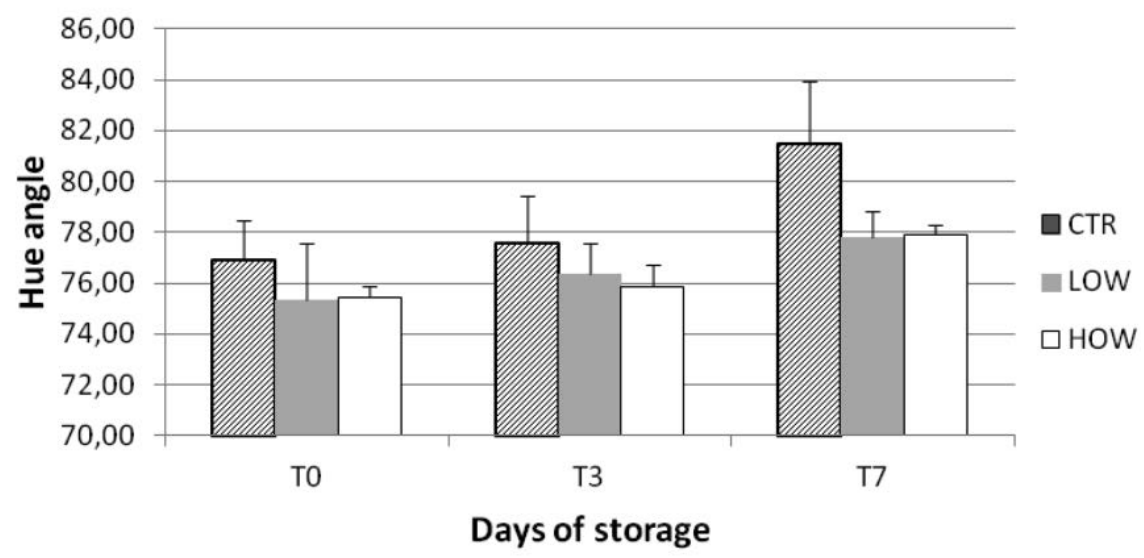

Figure 2. Effect of storage time on Hue angle of breast meat muscle stored at $4^{\circ} \mathrm{C}$. 
(2013), who reported that POV values of cooked pork patties added with natural polyphenols, increased and thereafter decreased with the time of storage and highlighted that the decomposition of hydroperoxides into secondary products resulted delayed in treated samples.

Meat from animals fed dietary OW supplementation showed lower TBARS values during storage when compared to the control group. These results agree with other authors who found a reduction of lipid oxidation measured trough TBARS during storage in lamb and beef muscles after olive oil by-products dietary supplementation (Luciano et al., 2013; Branciari et al., 2015a). Tufarelli et al. (2016) found an improved antioxidant defense system and a reduced TBARS level in chicken liver following dietary supplementation with extra virgin olive oil. Other authors have reported the beneficial effects of olive polyphenols on the oxidative status of meat measured through TBARS (Dal Bosco et al., 2012; Branciari et al., 2017), demonstrating their antioxidant effect in meat of animals fed olive phenolic compounds.

The extent of protein oxidation was evaluated by the formation of protein carbonyls. There are many reports on the biochemical changes in different meats during storage, most of which have focused on lipid oxidation (Abdel-Kader, 1996; Pikul et al., 1984). Little work has been done on protein oxidation of meat obtained from animal fed natural antioxidant. Zhang et al. (2011) reported an increase in lipid and protein oxidation in the breast muscles of birds that had been fed an oxidized oil diet compared to antioxidant-supplemented and control diets. Jongberg et al. (2011) demonstrated the positive effect of grape extract on protein oxidation in chill stored beef patties. A significant decrease in carbonyl formation in meat added $3 \%(\mathrm{w} / \mathrm{w})$ plant fruit extracts compared to control burger patties was observed in the study by Ganhão et al. (2010). Protein oxidation has been shown to induce a number of changes in proteins, such as modification of amino acid side chains, formation of protein polymers, loss of solubility, increase in carbonyl groups, change in amino acid composition and increase in proteolytic susceptibility (Levine et al., 1990; Xiong, 2000). This modification of muscle proteins, because of denaturation and proteolysis, induces changes in meat quality including texture traits, colour, aroma, flavor and water-holding capacity.

Considered the foregoing it is clear that lipid and protein oxidations are closely associated with deteriorative processes able to affect the overall quality of meat and meat products.

Meat colour was not affected by the phenolic compounds, contrary to what was observed in meat of other species (Branciari et al., 2015a). This result might be due to the characteristics of $P$. major muscle which is mainly composed by $\alpha$-white fibres that contain a lower amount of iron compared to the $\alpha$-red or $\beta$-red type fibres and for this reason are less susceptible to colour modification (Branciari et al., 2015b).

The results obtained from $\mathrm{ORAC}_{\mathrm{FL}}$ assay showed the increased antioxidant activity of treated groups compared to control.

The effect of dietary OW on meat antioxidant activity might be related to several factors, including the presence of bioactive molecules in tissues (muscle and liver) of animal fed with olive oil polyphenols as reported by Branciari et al. (2017). Indeed, there is evidence that polyphenols supplementation can exert a protective effect on $\alpha$-tocopherols, a defensive barrier against lipid oxidation from oxidative decay (Bars-Cortina et al., 2018). In addition, polyphenols were shown to affect the expression of genes involved in lambs' stress response and in primary homeostasis pathways, in both liver and muscle, increasing the expression of MYLK genes and improving the meat quality in female lambs (Sabino et al., 2018).

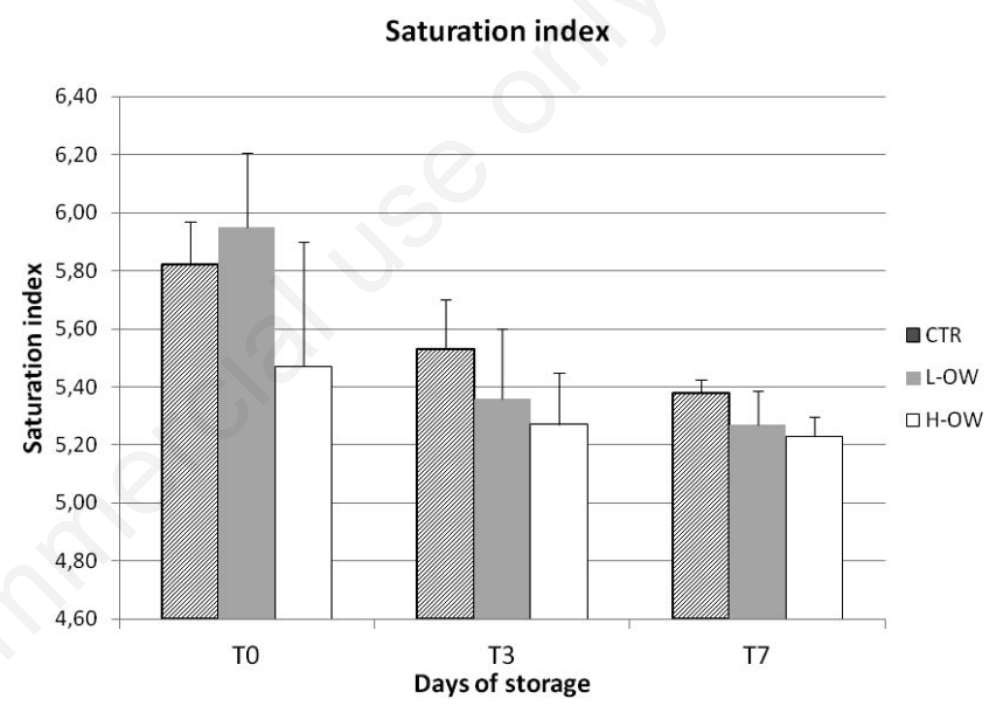

Figure 3. Effect of storage time on Saturation index of breast meat stored at $4^{\circ} \mathrm{C}$.

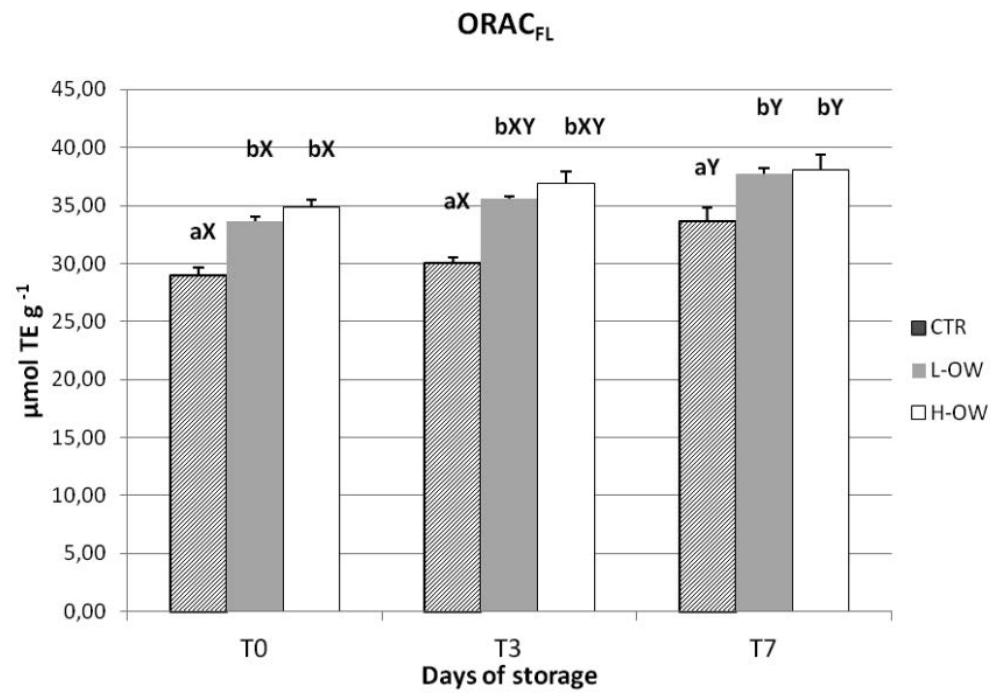

Figure 4. Effect of storage time on $\mathrm{ORAC}_{\mathrm{FL}}$ of breast meat stored at $4^{\circ} \mathrm{C}$. 
Dal Bosco A, Mourvaki E, Cardinali R, Servili M, Sebastiani B, Ruggeri S, Mattioli S, Taticchi A, Esposto S, Castellini C, 2012. Effect of dietary supplementation with olive pomaces on the performance and meat quality of growing rabbits. Meat Sci 92:783-8.

Ganhão R, Morcuende D, Estévez M, 2010. Protein oxidation in emulsified cooked burger patties with added fruit extracts: Influence on colour and texture deterioration during chill storage. Meat Sci 85:402-9.

Hwang KE, Choi YS, Choi SM, Kim HW, Choi JH, Lee MA, Kim CJ, 2013. Antioxidant action of ganghwayakssuk (Artemisia princeps Pamp.) in combination with ascorbic acid to increase the shelf life in raw and deep fried chicken nuggets. Meat Science 95: 593-602.

Abdel-Kader ZM, 1996. Lipid oxidation in chicken as affected by cooking and frozen storage. Mol Nut Food Res 40:21-4.

Bars-Cortina D, de las Hazas MCL, Benavent-Vallés A, Motilva MJ, 2018. Impact of dietary supplementation with olive and thyme phenols on alphatocopherol concentration in the muscle and liver of adult Wistar rats. Food funct 9:1433-43.

Branciari R, Ranucci D, Ortenzi R, Roila R, Trabalza-Marinucci M, Servili M, Papa P, Galarini R, Valiani A, 2016. Dietary administration of olive mill wastewater extract reduces campylobacter spp. Prevalence in broiler chickens. Sustainability 8:837.

Branciari R; Ranucci D, Miraglia D, Urbani S, Esposto S, Servili M, 2015a. Effect of dietary treatment with olive oil byproduct (olive cake) on physicochemical, sensory and microbial characteristics of beef during storage. Ital J Food Saf 4:225-9.

Branciari R, Ranucci D, Trabalza-Marinucci M, Codini M, Orru M, Ortenzi R, Forte C, Ceccarini MR, Valiani A, 2015b. Evaluation of the antioxidant properties and oxidative stability of Pecorino cheese made from the raw milk of ewes fed Rosmarinus officinalis L. leaves. Int J Food Sci Tech 50:558-65.

Branciari R, Galarini R, Giusepponi D, Trabalza-Marinucci M, Forte C, Roila R, Miraglia D, Servili M, Acuti G, Valiani A, 2017. Oxidative status and presence of bioactive compounds in meat from chickens fed polyphenols extracted from olive oil industry waste. Sustainability 9:1566.
Ou B, Hampsch-Woodill M, Prior RL, 2001. Development and validation of an improved oxygen radical absorbance capacity assay using fluorescein as the fluorescent probe. J Agr Food Chem 49:4619-26.

Pikul J, Lesczynski DE, Bechtel PJ, Kummerow FA, 1984. Effects of frozen storage and cooking on lipid oxidation in chicken meat. J Food Sci 49:838-43.

Ranucci D, Branciari R, Acuti G, Della Casa G, Trabalza-Marinucci M, Miraglia D, 2013. Quality traits of Ciauscolo salami from meat of pigs fed rosemary extract enriched diet. Ital J Food Saf 2:16.

Reznick AZ \& Packer L, 1994. Oxidative damage to proteins: Spectrophotometric method for carbonyl assay. Method Enzymol 233:357-63.

Roila R, Branciari R, Ranucci D, Ortenzi R, Urbani S, Servili M, Valiani, A, 2016. Antimicrobial activity of olive mill wastewater extract against Pseudomonas fluorescens isolated from mozzarella cheese. Ital J Food Saf 2:111.

Sabino M, Carmelo VAO, Mazzoni G, Cappelli K, Capomaccio S, AjmoneMarsan P, Verini-Supplizi A, Trabalza-Marinucci M, Kadarmideen HN 2018. Gene co-expression networks in liver and muscle transcriptome reveal sex-specific gene expression in lambs fed with a mix of essential oils. BMC Genom 19:236.

Tarladgis BG, Watts BM, Yonathan M, 1960. Distillation method for the determination of malonaldehyde in rancid foods. J Am Oil Chem Soc 37:44-8.

Tufarelli V, Laudadio V, Casalino E, 2016. An extra-virgin olive oil rich in polyphenolic compounds has antioxidant effects in meat-type broiler chickens. Environ Sci Pollut Res Int 23: 6197-204.

Xiao S, Zhang WG, Lee EJ, Ahn DU, 2013. Effects of diet, packaging and irradiation on protein oxidation, lipid oxidation of raw broiler thigh meat. Anim Industry Rep 659:12.

Xiong YL, 2000. Protein oxidation and implications for muscle food quality. Antioxidants in Muscle Foods: Nutritional Strategies to Improve Quality. Wiley and Sons, New York, NY, pp 85-90.

Zhang W, Xiao S, Lee EJ, Ahn DU, 2011. Consumption of oxidized oil increases oxidative stress in broilers and affects the quality of breast meat. J Agri Food Chem 59:969-74. 